\title{
Transcriptome Sequencing Uncovers the Avr5 Avirulence Gene of the Tomato Leaf Mold Pathogen Cladosporium fulvum
}

\author{
Carl H. Mesarich, ${ }^{1}$ Scott A. Griffiths, ${ }^{1}$ Ate van der Burgt, ${ }^{1}$ Bilal Ökmen, ${ }^{1}$ Henriek G. Beenen, ${ }^{1}$ \\ Desalegn W. Etalo, ${ }^{2}$ Matthieu H. A. J. Joosten, ${ }^{1}$ and Pierre J. G. M. de Wit ${ }^{1,3}$ \\ ${ }^{1}$ Laboratory of Phytopathology, and ${ }^{2}$ Laboratory of Plant Physiology, Wageningen University, Droevendaalsesteeg 1, 6708 \\ PB Wageningen, The Netherlands; ${ }^{3}$ Centre for BioSystems Genomics, P.O. Box 98, 6700 AB Wageningen, The Netherlands
}

Submitted 20 February 2014. Accepted 19 March 2014.

\begin{abstract}
The $C f-5$ gene of tomato confers resistance to strains of the fungal pathogen Cladosporium fulvum carrying the avirulence gene Avr5. Although $C f-5$ has been cloned, Avr5 has remained elusive. We report the cloning of Avr5 using a combined bioinformatic and transcriptome sequencing approach. RNA-Seq was performed on the sequenced race 0 strain (0WU; carrying $A v r 5)$, as well as a race 5 strain (IPO 1979; lacking a functional Avr5 gene) during infection of susceptible tomato. Forty-four in planta-induced $C$. fulvum candidate effector $(C f C E)$ genes of $0 \mathrm{WU}$ were identified that putatively encode a secreted, small cysteine-rich protein. An expressed transcript sequence comparison between strains revealed two polymorphic $C f C E$ genes in IPO 1979. One of these conferred avirulence to IPO 1979 on $C f$ 5 tomato following complementation with the corresponding OWU allele, confirming identification of Avr5. Complementation also led to increased fungal biomass during infection of susceptible tomato, signifying a role for Avr5 in virulence. Seven of eight race 5 strains investigated escape $C f-5$-mediated resistance through deletion of the Avr 5 gene. Avr5 is heavily flanked by repetitive elements, suggesting that repeat instability, in combination with $\mathrm{Cf}-5$-mediated selection pressure, has led to the emergence of race 5 strains deleted for the Avr5 gene.
\end{abstract}

Leaf mold disease of tomato (Solanum lycopersicum) is caused by the biotrophic Dothideomycete fungal pathogen Cladosporium fulvum (syn. Passalora fulva) (Thomma et al. 2005). The fungus enters the apoplastic space of tomato leaves through stomata, where it secretes a plethora of effector proteins. It is here that the outcome of an interaction between $C$. fulvum and tomato is determined, as governed by a gene-forgene relationship. According to this relationship, a C. fulvum

\section{S. A. Griffiths and A. van der Burgt contributed equally to this work.}

GenBank accession numbers KJ452245 and KJ452246 and RNA-Seq Sequence Read Archive BioSample accession numbers SAMN02642556, SAMN02642557, SAMN02642558, SAMN02642559, SAMN02642560, SAMN02642561, and SAMN02642562.

Corresponding authors: Carl H. Mesarich (E-mail: carl.mesarich@wur.nl) and Pierre J. G. M. de Wit (E-mail: pierre.dewit@wur.nl)

* The $\boldsymbol{e}$-Xtra logo stands for "electronic extra" and indicates that four supplementary figures and three supplementary tables are published online.

(C) 2014 The American Phytopathological Society effector gene product itself or its modulated host target is perceived by the product of a corresponding tomato $C$. fulvum resistance gene (de Wit 1992; de Wit et al. 2009b). In a compatible interaction (i.e., in the absence of corresponding $C$. fulvum resistance genes), these effectors function as virulence factors involved in modulating host defense responses (Bolton et al. 2008; de Jonge et al. 2010; Laugé et al. 1997; Ökmen et al. 2013; van Esse et al. 2007, 2008). However, in an incompatible interaction, C. fulvum resistance protein-mediated effector perception elicits a hypersensitive response (HR), a localized form of cell death that renders the pathogen avirulent by arresting fungal growth (de Wit et al. 2009b). Hence, the recognized effector is termed an avirulence (Avr) protein, and is encoded by an Avr gene. Notably, several types of sequence modification in the Avr genes of C. fulvum have been shown to result in the circumvention of $C$. fulvum resistance protein-mediated effector perception. These include gene deletion, insertion of a transposon-like element, point mutation (single nucleotide polymorphism [SNP] that provides a nonsynonymous amino acid [aa] substitution), or insertion or deletion [indel] of one or more nucleotides that result in a frame-shift mutation) (Stergiopoulos et al. 2007a).

To date, 12 C. fulvum effector genes have been cloned, and all encode a protein possessing an $\mathrm{N}$-terminal signal peptide for secretion into the apoplastic space of tomato (Bolton et al. 2008; Joosten et al. 1994; Laugé et al. 2000; Luderer et al. 2002; Ökmen et al. 2013; Stergiopoulos et al. 2012; van den Ackerveken et al. 1993; van Kan et al. 1991; Westerink et al. 2004). Furthermore, the majority, including all cloned Avr genes, encode a protein of less than 300 aa in length, with four or more cysteine residues following the signal peptide cleavage site. Specifically, the nine known Avr proteins are Avr2, Avr4, Avr4E, Avr9, Ecp1, Ecp2-1, Ecp4, Ecp5, and Ecp6, whose perception is mediated by the corresponding C. fulvum resistance proteins Cf-2, Cf-4, Cf-4E, Cf-9, Cf-Ecp1, Cf-Ecp2, Cf-Ecp4, Cf-Ecp5, and Cf-Ecp6, respectively (de Wit et al. 2009b; Thomma et al. 2011). Three additional effectors (Ecp2-2, Ecp7, and CfTom1) have also been identified but, thus far, no tomato accessions have been found that give an HR upon their specific perception (Bolton et al. 2008; Ökmen et al. 2013; Stergiopoulos et al. 2012).

An intrinsic virulence function has been determined for 4 of the 12 known effectors. Of these, Avr2 and Avr4 provide protection against enzymes deployed by the host as a form of basal defense. Specifically, Avr2 targets and inhibits four tomato cysteine proteases (Rcr3, Pip1, aleurain, and TDI-65) that presumably degrade or process C. fulvum proteins (Krüger et al. 2002; Rooney et al. 2005; Shabab et al. 2008; van Esse et al. 
2008), while Avr4 binds chitin present in the fungal cell wall, protecting it from hydrolysis by host chitinases (van den Burg et al. 2004, 2006; van Esse et al. 2007). The third functionally characterized effector, Ecp6, is a LysM domain-containing protein that sequesters chitin fragments released from the fungal cell wall of invading hyphae. This is achieved by outcompeting host chitin receptors for the binding of chitin fragments, which, in turn, prevents chitin-triggered immunity (de Jonge et al. 2010; Sánchez-Vallet et al. 2013). Finally, CfTom1 is a glycosyl hydrolase family 10 (GH10) enzyme that degrades the antifungal glycoalkaloid $\alpha$-tomatine to the less fungi-toxic compound tomatidine (Ökmen et al. 2013).

Thus far, all cloned $C$. fulvum resistance genes belong to one of two multigene families designated homologues of Cladosporium resistance genes $C f-2$ and $C f-9$ (Hcr 2 and $H c r 9$, respectively) (Rivas and Thomas 2005). Each encodes a receptor-like protein-type cell surface receptor containing extracytoplasmic leucine-rich repeats (LRR) (thought to directly or indirectly perceive C. fulvum Avr proteins), a membrane-spanning domain, and a short cytoplasmic tail (Kruijt et al. 2005). In total, six $C$. fulvum resistance genes have been cloned, including $C f-2$, $C f-4, C f-4 E$, and $C f-9$, as well as two $C$. fulvum resistance genes for which the corresponding $A v r$ genes have not yet been identified (de Wit et al. 2009b). One of these is Cf-5 (Hcr2-5C), which belongs to the Hcr2 gene family that also includes $C f-2$ and governs resistance to strains of $C$. fulvum carrying the Avr5 Avr gene (Dixon et al. 1998). Domain swap experiments between the Cf- 2 and Cf-5 proteins have demonstrated that specificity for Avr5 is confined to the region spanning LRR 3 to 21 (Seear and Dixon 2003). Furthermore, it is known that $H c r 2-5 D$, which is adjacent to $C f-5$ as part of an Hcr 2 gene cluster and encodes a protein almost identical to Cf-5, does not confer resistance to $C$. fulvum. Compared with Cf-5, Hcr2-5D possesses two additional LRR and further varies by a single aa difference adjacent to these repeats. It has been proposed that this two-LRR insertion disrupts a region required for the direct or indirect perception of Avr5 (Dixon et al. 1998).

To further understand how C. fulvum facilitates infection and to set a foundation for future experiments aiming to dissect the mechanism of Avr5 perception by Cf-5, we sought to clone the $A v r 5$ gene. However, whereas most Avr genes of this fungus have been cloned using a reverse-genetics approach, repeated attempts to clone Avr5 in this way have proven unsuccessful. This is despite presence of the Avr5 gene product in apoplastic fluid samples harvested from a compatible $C$. fulvum-tomato interaction (de Wit and Spikman 1982). For this reason, an alternative approach was pursued. RNA-Seq has emerged as a powerful tool for the identification of (candidate) $A v r$ genes from phytopathogenic fungi (Bruce et al. 2014; Cantu et al. 2013; de Jonge et al. 2012; van de Wouw et al. 2013). In this study, we report the use of a combined bioinformatic and RNA-Seq-based transcriptome sequencing approach to clone the Avr5 gene. We then determine the expression profile of this gene during infection of susceptible tomato, and go on to show that Avr5 is a virulence factor of $C$. fulvum. Based on allelic variation experiments, the mechanism with which this fungus circumvents Cf-5-mediated effector perception is discussed. Our study shows that an expressed transcript sequence comparison between candidate effector genes of different fungal races is a particularly powerful strategy for the identification of Avr genes.

\section{RESULTS}

A combined bioinformatic and transcriptome sequencing approach identifies 44 C. fulvum candidate effector genes.

$C$. fulvum candidate effector $(C f C E)$ genes of the sequenced race 0 strain ( $0 \mathrm{WU}$; carrying $A v r 5$ and all cloned $C$. fulvum effector genes) (de Wit et al. 2012) were identified as a starting point for the discovery of Avr5. We reasoned that Avr5 should encode a protein with features typical of all previously identified $C$. fulvum Avr proteins. Therefore, as a prerequisite for selection, $C f C E$ genes were required to encode a protein of $\leq 300$ aa in length, with a putative N-terminal signal peptide, and $\geq 4$ cysteine residues following the predicted signal peptide cleavage site. In addition, proteins were not permitted to possess a predicted transmembrane domain or glycosylphosphatidylinositol (GPI) anchor for integration into the fungal plasma membrane or attachment to the fungal plasma membrane or cell wall, respectively. Initially, 271 $C f C E$ genes, as previously identified by de Wit and associates (2012), met these criteria. Next, because fungal effector genes are notoriously difficult to predict (Hacquard et al. 2012), RNA-Seq was used to confirm exon-intron boundaries for each of the $271 C f C E$ gene models and to locate additional $C f C E$ genes in regions of the genome without a prediction but with transcriptome coverage (i.e., evidence of expression). This was a necessary step, because the $C$. fulvum effector genes Ecp1, Ecp4, and Ecp6 were incorrectly predicted and Avr2, Avr9, Ecp5, and Ecp 7 not predicted by the automated gene model prediction software used by de Wit and associates (2012) and van der Burgt and associates (2014). Indeed, five $C f C E$ genes were incorrectly predicted and an additional $11 C f C E$ genes not predicted (data not shown). This analysis increased the total number of $C f C E$ genes to 282.

To reduce the number of $C f C E$ genes by determining those most relevant to the $C$. fulvum-tomato interaction, RNA-Seq was used to identify those that are induced during infection of susceptible tomato when compared with expression during growth in vitro. Specifically, $C f C E$ genes were required to have a maximum RNA-Seq fragments per kilobase of exon per million fragments mapped (FPKM) value of $\geq 1,000$ at 4,8 , or 12 days postinoculation (dpi) in planta. Furthermore, this value had to exceed their highest FPKM value in vitro (Gamborg B5 or potato-dextrose broth [PDB] liquid media) by a factor of at least 2. This threshold was based on peak FPKM values observed for all previously cloned $C$. fulvum Avr genes (Supplementary Table S1). Importantly, because no biological replicates were used to generate RNA-Seq data, we confirmed that all previously cloned $A v r$ genes of this fungus are induced in planta during infection of susceptible tomato compared with expression during growth in vitro by means of a reverse-transcription quantitative real-time polymerase chain reaction (RT-qrtPCR) experiment (Supplementary Fig. S1). In this way, we were confident that RNA-Seq FPKM values calculated in this study could be used as a tool for the identification of in planta-induced

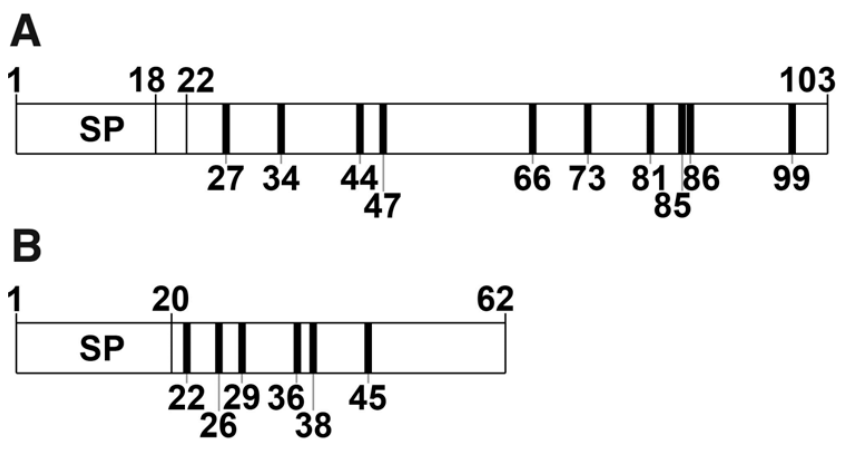

Fig. 1. Schematic representation of the predicted CfCE1 and CfCE2 proteins from strain 0WU of Cladosporium fulvum. The predicted A, CfCE1 and B, CfCE2 proteins contain a putative signal peptide (SP) for extracellular targeting to the apoplastic space of tomato, and are cysteine-rich. Predicted SP cleavage sites and cysteine residues are shown by thin and thick vertical black bars, respectively. Numbers indicate amino acid positions. 
$C f C E$ genes. According to this RNA-Seq expression analysis, the total number of $C f C E$ genes was reduced to 44 .

\section{An expressed transcript sequence comparison} reveals two candidate $A v r 5$ genes.

To identify candidate Avr5 genes, an RNA-Seq-based transcript sequence comparison for each of the $44 C f C E$ open reading frames (ORF) was carried out between strains OWU and IPO 1979 (lacking a functional Avr5 gene but carrying all cloned $C$. fulvum effector genes). We first set out to determine whether all CfCE genes are expressed in strain IPO 1979, because it was possible that $C f-5$-mediated resistance may be overcome by elimination of $A v r 5$ gene expression. However, all $C f C E$ genes, like the two reference housekeeping genes of $C$. fulvum investigated in this analysis (actin and $\beta$-tubulin), had RNA-Seq reads assigned to them, confirming that they are indeed expressed.
This result also established that none of the $C f C E$ genes had been deleted in strain IPO 1979. We then focused on identifying DNA polymorphisms that alter the protein-coding sequence in the 44 different $C f C E$ genes between the two strains. Sequence comparisons revealed that two $C f C E$ genes, $C f C E 1$ and $C f C E 2$, which also happen to be the most highly expressed $C f C E$ genes in planta according to FPKM values, carry a mutation that alters the protein-coding sequence in strain IPO 1979. These mutations were subsequently confirmed by direct sequencing of purified $C f C E 1$ and $C f C E 2$ PCR products following amplification from strain IPO 1979 genomic DNA. Therefore, CfCE1 and $C f C E 2$ were selected as candidates for Avr5.

The CfCE1 gene of strain OWU (Joint Genome Institute [JGI] ID 193707) is 544 nucleotides (nt) in length, comprising five exons $(66,65,112,43$, and $26 \mathrm{nt})$ and four introns $(51,68$, 48, and $65 \mathrm{nt}$ ) (Supplementary Fig. S2). The 312-nt CfCE1

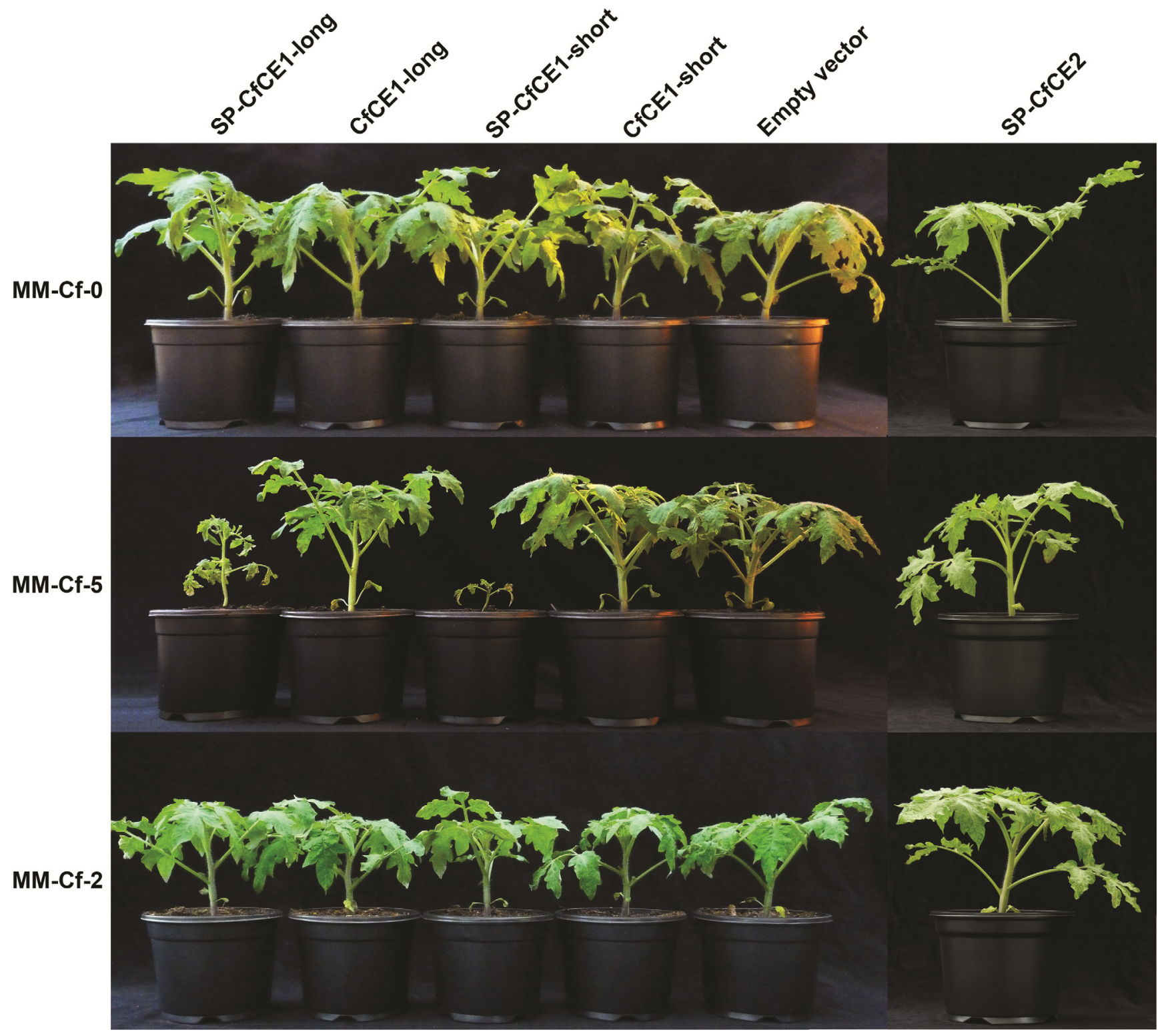

Fig. 2. CfCE1 triggers a systemic hypersensitive response in the MM-Cf-5 tomato line. Potato virus $X$ (PVX)-mediated expression of SP-CfCE1-long and SP-CfCE1-short (comprising the Nicotiana tabacum PR1A signal peptide [SP] fused to the long or short mature CfCE1 protein, respectively) elicits a systemic hypersensitive response (HR) in MM-Cf-5 (carrying only the $C f-5$ resistance gene) but not MM-Cf-2 (carrying only the $C f-2$ resistance gene) or MM-Cf-0 (carrying no $\mathrm{Cf}$ resistance genes). However, expression of CfCE1-long and CfCE1-short (comprising the long or short mature CfCE1 protein, respectively, with no SP), like the empty vector control (pSfinx; no insert), does not elicit an HR across any tomato lines tested but, instead, causes mosaic symptoms commonly associated with PVX infection. Likewise, expression of SP-CfCE2 (comprising the PR1A SP fused to the mature CfCE2 protein) in MM-Cf-5 or any other tomato line tested does not trigger an HR. Plants were photographed at 3 weeks postinoculation. 
ORF encodes a predicted protein of 103 aa with 10 cysteine residues (Fig. 1A). An N-terminal signal peptide of 18 or 22 aa was predicted by SignalP v3.0, while a 22 -aa N-terminal signal peptide was exclusively predicted by SignalP v4.1. According to these predictions, the presence or absence of four N-terminal aa residues (SYDA) following the signal peptide cleavage site results in a long or short mature CfCE1 protein ( 85 or 81 aa, respectively). When compared with strain OWU, the $C f C E 1$ ORF of strain IPO 1979 was found to possess a dinucleotide insertion (TC) at position 11, giving a +2 frameshift mutation and resulting in a premature stop codon after the 18th nucleotide (position seven of the signal peptide aa sequence). Thus, in effect, the $C f C E 1$ gene has been pseudogenized in strain IPO 1979. The $C f C E 2$ gene of strain OWU (no JGI ID) is 278 nt in length, comprising two exons (120 and $69 \mathrm{nt})$ and a single intron ( $89 \mathrm{nt})$. The $189-\mathrm{nt}$ ORF encodes a predicted protein of 62 aa with six cysteine residues and a putative N-terminal signal peptide of 20 aa predicted by SignalP v3.0 and v4.1

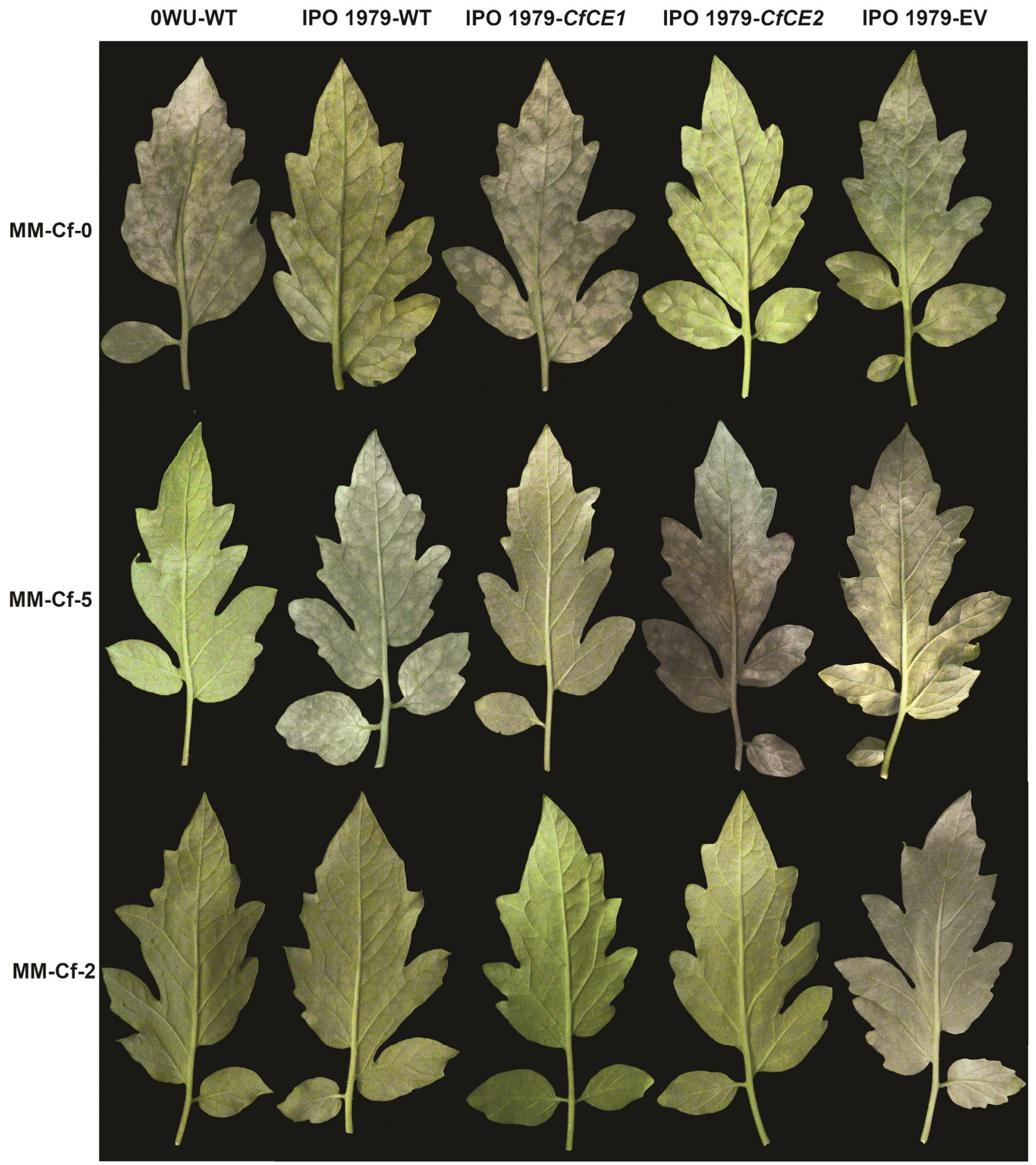

Fig. 3. Strain IPO 1979 of Cladosporium fulvum complemented with the $C f C E 1$ gene allele of strain $0 \mathrm{WU}$ is avirulent on the MM-Cf-5 tomato line. Inoculation of MM-Cf-0 (carrying no $C f$ resistance genes) but not of MM-Cf- 2 and MM-Cf-5 (carrying only the $C f-2$ and $C f$ - 5 resistance gene, respectively) with $C$. fulvum wild-type (WT) strain 0WU (carrying Avr2 and Avr5) results in a compatible interaction. Likewise, inoculation of MM-Cf-0 and MM-Cf-5 but not of MM-Cf-2 with WT strain IPO 1979 (carrying Avr2 but lacking a functional Avr5 gene), as well as the empty vector (EV) (pFBTS1; no insert) transformant of this strain, results in a compatible interaction. However, inoculation of MM-Cf-5 with all $C f C E 1$ transformants but not the $C f C E 2$ transformants of strain IPO 1979 results in an incompatible interaction. Leaves were photographed at 2 weeks postinoculation. Only transformants $C f C E 1-2.1$ and $C f C E 2-4.1$ are shown. 
(Fig. 1B). Upon comparison with strain OWU, the CfCE2 ORF of strain IPO 1979 was found to possess a single nonsynonymous mutation at position $73(\mathrm{CAT} \rightarrow \mathrm{GAT})$, resulting in a Histo-Asp aa substitution at position 25 of the predicted protein sequence. The CfCE1 and CfCE2 proteins displayed no significant homology to sequences deposited in public databases or with other $C$. fulvum effectors. Furthermore, no potential

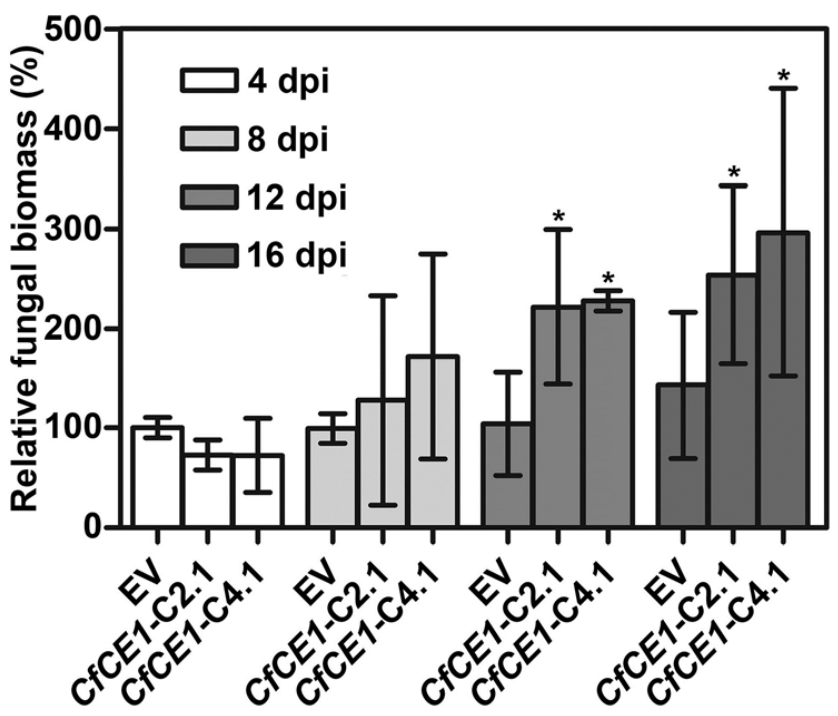

Fig. 4. Avr5 is a virulence factor of Cladosporium fulvum. The virulence of the wild-type $C$. fulvum race 5 strain IPO 1979, independent Avr5-complemented transformants, as well as an empty vector (EV) (pFBTS1; no insert) transformant of this strain, was assessed during a compatible interaction with MM-Cf-0 tomato. For this purpose, C. fulvum biomass at 4, 8, 12 , and 16 days postinoculation (dpi) was assessed by a quantitative realtime polymerase chain reaction experiment and was based on amplification of the C. fulvum actin gene in $100 \mathrm{ng}$ of total genomic DNA from each sample. The Solanum lycopersicum ribulose-1, 5-bisphosphate carboxylase/oxygenase (rubisco) gene was used for sample calibration. For each time point, fungal biomass was plotted relative to that of wild-type, which was set to $100 \%$. A two-way analysis of variance was performed, followed by a Fisher's least significant difference test, with only statistically significant differences indicated $(*=P<0.01)$ when compared with both wild-type and the EV transformant. Error bars represent the standard deviation of three biological replicates. Only transformants $C f C E 1-2.1$ and CfCE1-4.1 are shown. protein homologs could be identified with an identical or similar cysteine spacing profile.

CfCE1 but not CfCE2 triggers a Cf-5-specific HR.

To determine whether CfCE1 or CfCE2 can elicit a Cf-5-specific HR, the Potato virus $X$ (PVX)-based expression system (Hammond-Kosack et al. 1995; Takken et al. 2000) was employed to systemically deliver each CfCE protein into the 'Moneymaker' (MM) lines MM-Cf-0 (no C. fulvum ressitance genes), MM-Cf-2 ( $C f$-2 gene), or MM-Cf-5 ( $C f-5$ gene) following agroinfection. As expected, inoculation of all tomato lines with PVX expressing the empty vector pSfinx (negative control; no insert) resulted only in systemic mosaic symptoms commonly associated with PVX infection (Fig. 2) (Hammond-Kosack et al. 1995). However, inoculation of MM-Cf-5 but not of MM-Cf-0 with PVX::SP-CfCE1-short or PVX::SP-CfCE1-long (encoding the Nicotiana tabacum pathogenesis-related 1A [PR1A] signal peptide fused to the short or long version of the mature CfCE1 protein, respectively) resulted in a systemic HR (Fig. 2). This result was specific for CfCE1, because inoculation of MM-Cf-5 with PVX::SP-CfCE2 (encoding the PR1A signal peptide fused to the mature CfCE2 protein) resulted only in mosaic symptoms (Fig. 2). The HR elicited by SP-CfCE1-short was much stronger than that induced by SP-CfCE1-long, as shown by increased chlorosis and necrosis as well as enhanced stunting of MM-Cf-5 growth (Fig. 2). By 4 weeks postinoculation, PVX::SP-CfCE1short-inoculated plants had died (results not shown). In contrast, inoculation of MM-Cf-5, like that of MM-Cf-0, with PVX:: $C f C E 1$-short or PVX::CfCE1-long (encoding the short or long mature CfCE1 protein, respectively, with no signal peptide) did not result in a systemic HR but, instead, only mosaic symptoms (Fig. 2). These results suggest that CfCE1 must be secreted extracellularly to elicit an HR and is consistent with extracellular perception by $\mathrm{Cf}-5$, given that $\mathrm{Cf}-5$ is putatively localized to the host plasma membrane (Dixon et al. 1998). Furthermore, these results support the 22-aa signal peptide as the genuine sequence required for the targeting of CfCE1 to the host apoplast, and indicate that the four additional $\mathrm{N}$-terminal aa residues present in CfCE1-long prevent full perception of CfCE1. To further confirm the specificity of CfCE1 for Cf-5, the complete set of recombinant PVX::SP-CfCE1 and PVX::CfCE1 viruses was inoculated into MM-Cf-2. However, only mosaic symptoms were observed (Fig. 2). Collectively, these results show that CfCE1, rather than CfCE2, elicits a Cf-5-specific HR.

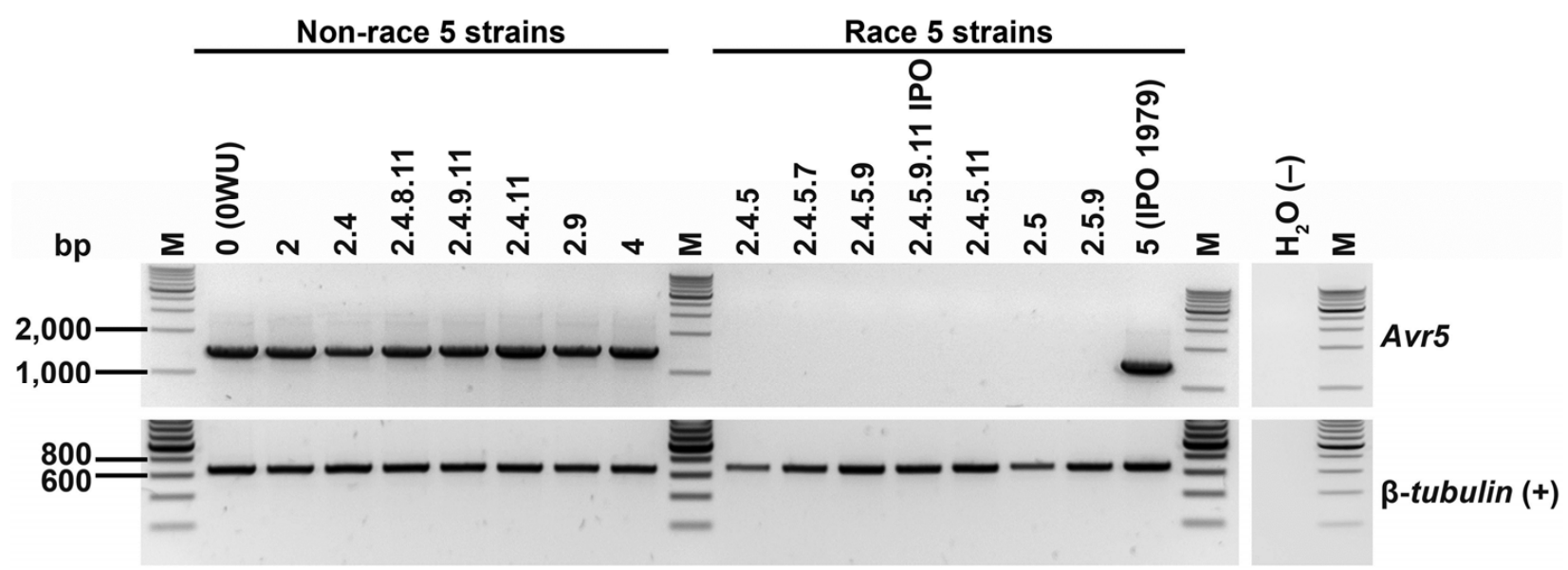

Fig. 5. Deletion of the Avr5 gene is the predominant mechanism for overcoming $C f$-5-mediated resistance. A polymerase chain reaction (PCR)-based presence-or-absence screen across race 5 and non-race 5 strains of Cladosporium fulvum shows that the Avr 5 gene is present across all non-race 5 strains but deleted across all but one race 5 strain investigated. However, the $C$. fulvum $\beta$-tubulin gene (positive control) is present across all strains investigated, regardless of race status. Strain numbers represent race status; $\mathrm{M}=200$ - or 1 -kb DNA Step Ladder marker, $-=\mathrm{H}_{2} \mathrm{O}$ negative control, and $+=C$. fulvum $\beta$ tubulin positive control. Expected PCR amplicon sizes: Avr5 = 1,737 bp and $\beta$-tubulin $=674 \mathrm{bp}$. 
Race 5 complemented with the $C f C E 1$ gene is avirulent on MM-Cf-5 tomato.

Race 5 strains of $C$. fulvum are able to circumvent $C f-5$-mediated resistance due to the absence of a functional Avr5 gene and, thus, are able to infect tomato lines carrying the $C f-5$ gene. Therefore, a complementation assay was carried out to determine whether the $C f C E 1$ or $C f C E 2$ gene from strain $0 \mathrm{WU}$ (each under the control of their native promoter) can confer avirulence to strain IPO 1979 on MM-Cf-5. As expected, inoculation of MM-Cf- 0 with all wild-type and transformant strains of C. fulvum resulted in infection (compatible interaction) and of MM-Cf-2 in lack of infection (incompatible interaction) (Fig. 3). Again, as expected, inoculation of MM-Cf-5 with wild-type IPO 1979, and the empty vector (pFBTS1; no insert) transformant of this strain but not wild-type 0WU resulted in a compatible interaction (Fig. 3). However, inoculation of MM-Cf-5 with pFBTS1::CfCE1 transformants of IPO 1979 resulted in an incompatible interaction (Fig. 3). In contrast, inoculation of MM-Cf-5 with pFBTS1::CfCE2 transformants of IPO 1979 resulted in a compatible interaction (Fig. 3). Therefore, CfCE1 is the gene responsible for the avirulent phenotype of $C$. fulvum on MM-Cf-5 and was accordingly renamed Avr5.

\section{Avr5 is a virulence factor of $C$. fulvum.}

To determine whether Avr5 is a virulence factor of $C$. fulvum, transformants of IPO 1979 complemented with a single functional copy of the Avr5 gene (Supplementary Fig. S3) were inoculated onto MM-Cf- 0 and the amount of fungal biomass assessed by a qrtPCR experiment at $4,8,12$, and 16 dpi. Although similar at 4 and $8 \mathrm{dpi}$, a statistically significant increase in fungal biomass was observed for Avr5-complemented transformants at 12 and $16 \mathrm{dpi}$, relative to both wild-type IPO 1979 and the empty vector transformant of this strain (Fig. 4). These data show that Avr5 is a virulence factor of C. fulvum.

\section{Strains of C. fulvum predominantly overcome}

$C f$-5-mediated resistance through deletion of the Avr 5 gene.

A PCR screen was employed to investigate the presence or absence of the Avr5 gene across the genomes of 16 C. fulvum strains. These included eight race 5 and eight non-race 5 strains of this fungus that are virulent and avirulent, respectively, on MM-Cf-5. A PCR primer pair flanking the Avr5 coding sequence and incorporating 709 and 199 bp of $5^{\prime}$ and $3^{\prime} A v r 5$ noncoding regions (NCR) generated a genomic DNA amplicon across all avirulent strains but failed to give an amplicon for all but one virulent strain (IPO 1979; frameshift mutation) (Fig. 5 ). This implies that, in the majority of race 5 strains investigated, the Avr5 gene has been deleted. The absence of an Avr5 PCR amplicon was not due to poor-quality genomic DNA, because the C. fulvum $\beta$-tubulin gene (positive control) could be amplified by PCR from the genomic DNA of all strains tested, regardless of their race status (Fig. 5). As such, deletion of the Avr 5 gene by $C$. fulvum is the predominant mechanism for overcoming $C f$-5-mediated resistance. We then set out to determine the extent of allelic variation present at the Avr 5 locus for all eight strains of $C$. fulvum avirulent on MM-Cf-5, as well as strain IPO 1979 virulent on MM-Cf-5. This analysis was based on a 1,452-bp PCR amplicon that included the Avr5 ORF and introns as well as the NCR described above. However, no additional allelic variation was observed (results not shown).

\section{The Avr 5 gene is surrounded by repetitive elements.}

The Avr5 gene is located on a small, 15,472-nt scaffold (scaffold 7180000130711) and is completely surrounded by a mosaic of repetitive elements (Supplementary Fig. S4). However, these elements could not be assigned to a particular repeat class present in the National Center for Biotechnology Infor- mation (NCBI) NR sequence database or RepBase, which is due, in part, to the extensive presence of repeat-induced point mutations (de Wit et al. 2012). The G+C content across the entire scaffold is almost identical: the $\mathrm{G}+\mathrm{C}$ content from the start to termination codon of $A v r 5$ is $47.06 \%$ and for the rest of the scaffold is $47.08 \%$.

\section{Avr 5 expression is strongly induced in planta} and weakly induced during nitrogen starvation in vitro.

RNA-Seq FPKM values revealed that Avr 5 expression is strongly induced during infection of susceptible tomato and weakly induced during growth in vitro under conditions of nitrogen deprivation (Gamborg B5-N) when compared with expression during growth in vitro in PDB or Gamborg B5 liquid media (CfCE1). Indeed, an RT-qrtPCR experiment confirmed that Avr5 is strongly induced throughout infection (peaking at $12 \mathrm{dpi}$ ) and weakly induced in Gamborg B5-N liquid medium, while expression of this gene was not detected during growth in PDB or Gamborg B5 liquid media (Fig. 6). A similar expression profile has already been shown for Avr9 but, thus far, no other $C$. fulvum Avr genes (Thomma et al. 2006; van den Ackerveken et al. 1994), and is appropriately reflected in our FPKM and RTqrtPCR data. It is known that the Avr9 promoter sequence carries several 5'-(TA)GATA-3' boxes within $0.6 \mathrm{~kb}$ upstream of its translation start site (van den Ackerveken et al. 1994). These, together with 5'-HGATAR-3' boxes (where H stands for A, T or C, and $\mathrm{R}$ for $\mathrm{A}$ or $\mathrm{G}$ ), are known to act as binding sites for GATAtype nitrogen-responsive transcriptional regulators $(\mathrm{Fu}$ and Marzluf 1990; Ravagnani et al. 1997; Snoeijers et al. 2003), including nitrogen response factor 1 (Nrf1) of C. fulvum (PérezGarcía et al. 2001). For this reason, we screened the Avr5 promoter region for $5^{\prime}$-(TA)GATA-3' and $5^{\prime}$-HGATAR-3' boxes. In total, $115^{\prime}$-(TA) GATA-3' boxes were found within $0.6 \mathrm{~kb}$ upstream of the Avr 5 translation start site. Eight of these also conform to the 5'-HGATAR-3' consensus sequence.

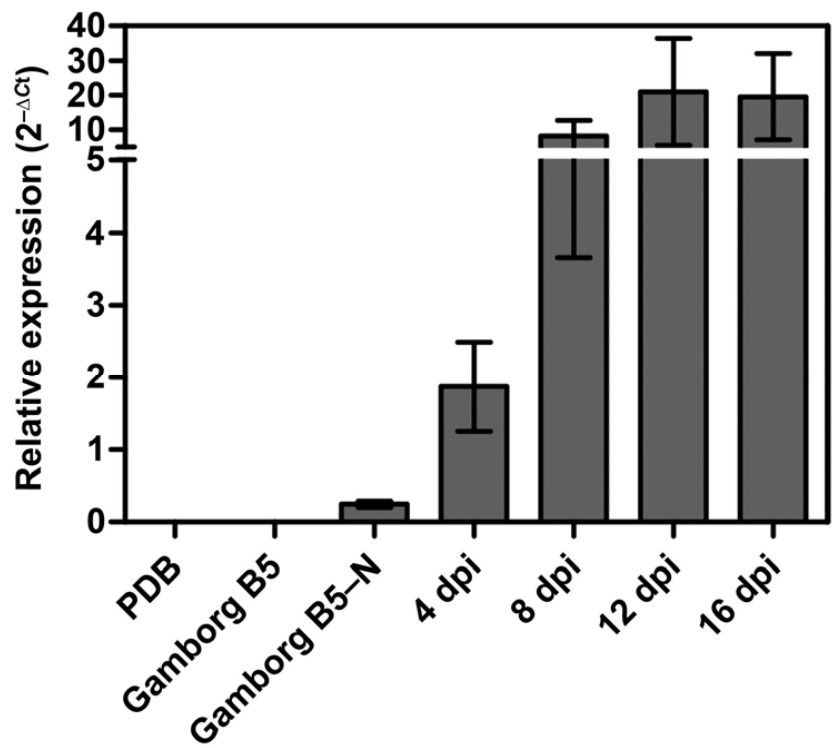

Fig. 6. The Avr5 gene of Cladosporium fulvum strain $0 \mathrm{WU}$ is strongly induced in planta and weakly induced in vitro under nitrogen starvation. Expression was monitored by a reverse-transcription quantitative real-time polymerase chain reaction experiment in planta during a compatible $C$. fulvum-Solanum lycopersicum 'Heinz' interaction at 4, 8, 12, and 16 days postinoculation (dpi), as well as in vitro in potato-dextrose broth (PDB), Gamborg B5, and Gamborg B5 minus nitrogen (Gamborg B5-N) liquid media. Expression was normalized to that exhibited by the C. fulvum actin gene according to the $2^{-\Delta \mathrm{Ct}}$ method. Error bars represent the standard deviation of three biological replicates. 


\section{DISCUSSION}

Effector proteins of $C$. fulvum function as virulence factors involved in enabling the infection of tomato but may also act as avirulence factors that trigger host defense (de Wit et al. 2009b; Thomma et al. 2005). Hence, their identification and functional characterization is of great importance to understanding the strategies employed by this fungus to establish disease, as well as the mechanisms involved in $C$. fulvum resistance protein-mediated effector perception by the host. In this study, we set out to clone the Avr5 gene of C. fulvum, corresponding to the previously cloned $C f-5$ resistance gene of tomato (Dixon et al. 1998).

Most known Avr genes of $C$. fulvum have been cloned using a reverse-genetics approach. However, repeated attempts to clone Avr5 in this way have proven unsuccessful. Consequently, an alternative strategy based on transcriptome sequencing was initiated. Transcriptome sequencing has emerged as a powerful tool for the identification of (candidate) Avr genes from phytopathogenic fungi (Bruce et al. 2014; Cantu et al. 2013; de Jonge et al. 2012; van de Wouw et al. 2013). For example, de Jonge and associates (2012) employed a combined genome and transcriptome sequencing approach to clone the Avel Avr gene of the vascular wilt fungus Verticillium dahliae, corresponding to the Vel resistance gene of tomato. Specifically, population genome sequencing uncovered a single $50-\mathrm{kb}$ region exclusive to avirulent strains of this fungus. Subsequent transcriptome sequencing of $V$. dahliae-infected $N$. benthamiana plants revealed a single highly expressed gene in this region, which was confirmed to be Avel by functional analyses (de Jonge et al. 2012). More recently, an integrated approach combining genomics, transcriptomics, and effector-focused bioinformatic annotations was used to identify candidate $A v r$ genes of Puccinia striiformis f. sp. tritici, the yellow (stripe) rust pathogen of wheat (Cantu et al. 2013). Of 2,999 genes encoding a putatively secreted protein, five candidate $A v r$ genes were identified that are specifically induced in haustoria and, based on a genomic sequence comparison, possess nonsynonymous mutations between two isolates that differ in their ability to infect wheat varieties carrying the YrRob or YrSol resistance gene (Cantu et al. 2013). In our study, a combined bioinformatic and transcriptome sequencing approach led to the identification of $44 C f C E$ genes of strain 0WU (carrying a functional $A v r 5$ gene) that are induced in planta and encode putative proteins with features typical of C. fulvum Avr proteins identified thus far. An expressed sequence comparison for each $C f C E$ ORF between strains OWU and IPO 1979 (lacking a functional Avr5 gene) identified two candidate $A v r 5$ genes with a proteinaltering mutation in strain IPO 1979. Subsequent functional analyses confirmed one of these genes as Avr5.

The success of our strategy raised an important question: why was Avr5 not originally identified using a reverse-genetics approach? Predating availability of the $C$. fulvum genome sequence, two-dimensional polyacrylamide gel electrophoresis followed by N-terminal aa sequencing was used to separate, visualize, and identify Avr5 candidates present in concentrated apoplastic fluid samples of a compatible $C$. fulvum-tomato interaction. However, no valuable sequence information could ever be retrieved for these candidates. Given the predicted molecular weight of the mature Avr5 protein (approximately 9 $\mathrm{kDa}$ ), it is expected that, in these experiments, Avr5 occupied a region of the gel highly populated with different protein species, and that this prevented successful N-terminal aa sequencing. Unfortunately, Avr5 was unable to be purified further, because elicitor activity (i.e., induction of a Cf-5-mediated HR) was lost during subsequent purification steps. In more recent efforts, proteins present in similar apoplastic fluid samples were digested with trypsin, and peptides analyzed by liquid chromatographytandem mass spectrometry (LC-MS/MS). Peptide sequences were then determined from a six-frame translation database of strain 0WU genome sequence. However, this approach, too, was unsuccessful for the identification of Avr5. Given the presence of Avr5 in RNA-Seq libraries of a compatible interaction, we reanalyzed preexisting LC-MS/MS data using a six-frame translation of this transcriptome sequence. For the first time, peptides (corresponding to approximately $70 \%$ of the predicted mature Avr5 protein sequence) were identified (results not shown). The inability to identify Avr5 in the genome database can be explained by two features absent from the corresponding transcriptome database. The first is intronic sequence, because Avr5 has four introns and three of these prevented the identification of independent peptides. The second is repetitive sequence, because Avr5 is more tightly associated with repetitive elements than any other $C$. fulvum effector gene identified to date, and the genome database was repeat-masked to reduce its size. Consequently, the $5^{\prime}$ and $3^{\prime}$ regions of the Avr5 gene, encoding $>50 \%$ of the mature protein sequence, were also masked.

Consistent with all previously cloned C. fulvum Avr genes, Avr5 is induced in planta, and encodes a small secreted protein with a high and even number of cysteine residues. These cysteine residues presumably form intramolecular disulfide bonds required for Avr5 stability and function in the protease-rich environment of the tomato apoplastic space, as has previously been shown for the cysteine residues of Avr2, Avr4, and Avr9 (van den Burg et al. 2003; van den Hooven et al. 2001; van't Klooster et al. 2011). In addition to demonstrating strong induction in planta, Avr5 is weakly induced under conditions of nitrogen deprivation in vitro. Until now, induction under both conditions had been reported for Avr9 but no other Avr genes of C. fulvum (Thomma et al. 2006; van den Ackerveken et al. 1994). Associated with this induction, and in common with Avr9 (van den Ackerveken et al. 1994), the promoter region of Avr5 was found to contain several potential binding sites for Nrf1, a GATA-type nitrogen-responsive transcriptional regulator of C. fulvum (Pérez-García et al. 2001). However, although difficult to predict, we expect, based on this weak level of induction, that nitrogen limitation represents, at most, a minor cue for the induction of Avr5 gene expression in planta.

In addition to encoding a secreted, small cysteine-rich protein, it has been shown that many cloned $C$. fulvum Avr genes occupy a repeat-rich chromosomal region of the strain $0 \mathrm{WU}$ genome (de Wit et al. 2012). This is also true for Avr5, which is surrounded by a mosaic of repetitive elements. Furthermore, Avr5 resides on a very small genome scaffold (approximately 15.5 $\mathrm{kb}$ ), suggesting the existence of large flanking repeats, which have hampered a longer scaffold assembly. It is known that several fungal $A v r$ genes located close to repetitive elements are susceptible to deletion, and that gene deletion is a common mechanism for overcoming host resistance (Gout et al. 2007). Indeed, adaptation of $C$. fulvum to resistant tomato cultivars through deletion of an Avr gene has previously been shown for Avr4E and Avr9 (van Kan et al. 1991; Westerink et al. 2004) which are, like Avr5, flanked by repetitive elements in the genome of strain OWU, and reside on a small genome scaffold of less than $20 \mathrm{~kb}$ in size (de Wit et al. 2012). Perhaps unsurprisingly, then, all but one race 5 strain of $C$. fulvum investigated in our study circumvents $C f$-5-mediated resistance through deletion of the Avr5 gene. This is similar to race 9 strains where, thus far, an absolute correlation exists between deletion of the $A v r 9$ gene and the breakdown of $C f$-9-mediated resistance (Stergiopoulos et al. 2007a; van Kan et al. 1991). As already hypothesized for Avr9 (de Wit et al. 2012), we expect that the enrichment of strains carrying an Avr5 deletion can be explained by the close proximity of this gene to large unstable repeats. It 
is anticipated that the mechanism of deletion involves homologous recombination between repetitive elements flanking the Avr 5 gene. Evidence for such a mechanism was recently provided for the AVR-Pia Avr gene of the rice blast fungus Magnaporthe oryzae, which is deleted across most isolates virulent on rice cultivars carrying the corresponding resistance gene Pia (Sone et al. 2013). Here, it appears that homologous recombination between flanking copies of the DNA-type transposon Occan results in the deletion of AVR-Pia.

Given the enrichment of race 5 strains carrying an Avr 5 gene deletion, it was somewhat surprising to identify a frameshift mutation in the Avr5 gene of strain IPO 1979. The identification of this exception, together with the fact that all strains avirulent on $C f-5$ tomato investigated in this study possess an identical Avr5 allele, suggest that deletion occurs more quickly than the accumulation of SNP and indels in this gene. In fact, this phenomenon may also be true for the Avr9 gene, because an extremely low number of SNP have been identified between strains avirulent on $C f-9$ tomato to date (Stergiopoulos et al. 2007a). Ultimately, this high level of repeat instability likely explains why $C f$-5-mediated resistance is so quickly overcome. As evidence of how quickly this occurs, the $C f-5$ resistance specificity was first identified in 1970 in S. lycopersicum var. cerasiforme and subsequently introgressed into S. lycopersicum (Kerr et al. 1971); however, by 1976, not long after its deployment in cultivated tomato, strains capable of breaking this resistance began to emerge (Hubbeling 1978; Laterrot and Clerjeau 1979; Laterrot et al. 1985; Stamova 1982).

Despite lacking a functional Avr5 gene, race 5 strains of $C$. fulvum have retained their ability to infect susceptible tomato. This would suggest that Avr5 is not essential to the virulence of this fungus. However, because complementation of strain IPO 1979 with a functional Avr5 allele leads to increased fungal biomass during infection of susceptible tomato, Avr5 does contribute to virulence and, therefore, is a virulence factor. The specific function of Avr5 in virulence, though, remains to be determined. Predicting the intrinsic virulence function of fungal effector proteins is often difficult due their lack of known conserved domains (de Wit et al. 2009a; Stergiopoulos and de Wit 2009). This is also true for Avr5, which displays no homology to sequences present in public databases or with other $C$. fulvum effectors. Mutagenesis studies have often been employed in an attempt to identify tomato genes absolutely required for $C$. fulvum resistance gene-mediated resistance, including those that encode virulence targets of the corresponding $C$. fulvum effector. For example, Dixon and associates (2000) used a mutagenesis-based approach to identify the "required for C. fulvum resistance 3" (Rcr3) gene of tomato, which encodes a cysteine protease that, when inhibited by Avr2, triggers Cf-2-mediated resistance (Rooney et al. 2005). Seear and Dixon (2003) carried out a similar mutagenesis study in an attempt to identify an $R c r$-like gene specifically required for $C f-5$-mediated resistance. However, no such gene could be identified. The authors gave three possible explanations for this result. First, only a relatively low number of mutagenized families were screened and, thus, relevant mutants may have been missed. Second, any Rcr-like gene specific for $C f-5$-mediated resistance may be redundant or encode an essential function, such that any mutation in this gene would not have been visible in this type of screen. Third, a direct rather that indirect interaction may occur between Cf-5 and Avr5 and, therefore, an Rcr-like protein is not involved (Seear and Dixon 2003). Certainly, Dixon and associates (2000) were able to determine, based on a cross between an $r c r 3$ mutant line and MM-Cf-5, that Rcr3 is not required for $C f-5$-mediated resistance (i.e., Rcr3 is not a common interacting partner of $\mathrm{Cf}-2$ and $\mathrm{Cf}-5$ ). Our results corroborate this finding, because Avr5 failed to trigger Cf-2-mediated resis- tance in MM-Cf-2 using the PVX-based expression system. Now that Avr5 has been identified, future experiments can focus on determining the virulence function of this effector. For example, a protein pull-down experiment with Avr5 can be employed to identify potential virulence targets in tomato. This may, in turn, give further insights into the mechanism of Avr5 perception by $\mathrm{Cf}-5$ (i.e., to determine whether $\mathrm{Cf}-5$ perceives Avr5 indirectly through a modulated host target). Alternatively, yeast two-hybrid or co-immunoprecipitation assays can be undertaken to determine whether Cf-5 and Avr5 interact directly.

In summary, we have harnessed the power of transcriptome sequencing to clone the Avr5 gene of $C$. fulvum, corresponding to the previously cloned $C f-5$ gene of tomato (Dixon et al. 1998). In doing so, we have set the foundation for future experiments aiming to determine the intrinsic virulence function of Avr5 and, thus, further understand the strategies employed by this fungus to establish disease.

\section{MATERIALS AND METHODS}

\section{Fungal strains and plant material.}

Strains of $C$. fulvum used in this study are shown in Supplementary Table S2. All strains were sourced from the worldwide collection of $C$. fulvum present at the Laboratory of Phytopathology, Wageningen University, The Netherlands (Iida et al. 2010; Stergiopoulos et al. 2007b). Tomato lines used in this study were $S$. lycopersicum (MM-Cf-0) and S. lycopersicum 'Heinz Cf-0' (H-Cf-0), which carry no C. fulvum resistance genes, and the near-isogenic MM-Cf-2 and MM-Cf-5 lines, which carry the $C f-2(C f-2.1$ and $C f-2.2)$ and $C f-5$ (Hcr2-5C) resistance genes, respectively, as part of an $\mathrm{Hcr} 2$ gene cluster (Dixon et al. 1996, 1998; Tigchelaar 1984).

\section{Deep RNA-Seq transcriptome sequencing and mapping.}

Four-week-old H-Cf-0 and MM-Cf-0 plants were inoculated with conidia of $C$. fulvum strains OWU and IPO 1979, respectively (compatible interactions). For this purpose, strains were cultured on potato-dextrose agar (Oxoid, Basingstoke, Hampshire, U.K.) for 2 to 3 weeks in the dark at $22^{\circ} \mathrm{C}$. Conidia were collected with distilled water, passed through Miracloth (EMD Millipore, Billerica, MA, U.S.A.) to remove fungal mycelia, and pelleted by centrifugation at $4,000 \times g$ for $8 \mathrm{~min}$. Conidia were washed with distilled water, collected by centrifugation once more, and diluted to a final concentration of $5 \times 10^{5}$ conidia $/ \mathrm{ml}$. To initiate infection, conidia were spray inoculated onto the abaxial surface of tomato leaves, and the plants were grown in plastic-covered cages for $48 \mathrm{~h}$ to ensure $100 \%$ relative humidity (RH), with a regime of light and darkness of 16 and $8 \mathrm{~h}$, respectively, and supplemental light at $100 \mathrm{~W} / \mathrm{m}^{2}$ when the sunlight influx intensity was less than $150 \mathrm{~W} / \mathrm{m}^{2}$. Cages were subsequently opened to allow disease development to progress under regular greenhouse conditions, with $70 \% \mathrm{RH}$, temperatures of 23 to $25^{\circ} \mathrm{C}$ during the day and 19 to $21^{\circ} \mathrm{C}$ during the night, and an identical light-and-dark regime. The fourth composite leaf of infected tomato plants was harvested at 4,8 , and 12 dpi for strain OWU and 6 dpi for strain IPO 1979 and immediately flash frozen in liquid nitrogen. For in vitro liquid cultures of strain 0WU, conidia were prepared as above, and diluted to a final concentration of $1 \times 10^{6}$ conidia/ml. Conidia $(1 \mathrm{ml})$ were used to seed $50 \mathrm{ml}$ of PDB (Oxoid), and cultured at $22^{\circ} \mathrm{C}$ and $150 \mathrm{rpm}$ for 4 days. Alternatively, C. fulvum was grown in PDB as above for 3 days and the mycelia was collected in Miracloth, washed with sterile distilled water, and transferred to Gamborg B5 liquid medium (Duchefa Biochemie BV, Haarlem, The Netherlands) supplemented with 2.0\% (wt/vol) sucrose (Gamborg B5) or Gamborg liquid medium without nitrogen (Gamborg B5-N) (van den Ackerveken et al. 1994) for an additional $24 \mathrm{~h}$ at $22^{\circ} \mathrm{C}$ 
and $150 \mathrm{rpm}$. Mycelia were collected as above, blot dried on filter paper, and flash frozen in liquid nitrogen. Samples were ground to a powder in liquid nitrogen, and total RNA was extracted from $100 \mathrm{mg}$ of material using $1 \mathrm{ml}$ of Trizol (Invitrogen, Carlsbad, CA, U.S.A.). RNA was treated with DNase I Amplification Grade (Invitrogen) and purified with an RNeasy mini kit (Qiagen, Benelux BV, Venlo, The Netherlands) as per the manufacturer's instructions. cDNA synthesis, library preparation (200-bp inserts), and Illumina sequencing (90-bp pairedend reads) for in vitro and in planta samples of strains 0WU and IPO 1979, respectively, were performed at the Beijing Genome Institute (Hong Kong) and, for in planta samples of strain 0WU (100-bp paired-end reads), at Plant Research International (Wageningen University, Wageningen, The Netherlands). Paired-end RNA-Seq reads of strain 0WU (approximately 30 million) were mapped to the strain 0WU genome sequence using TopHat v2.0.4 (Trapnell et al. 2009). Transcript assembly and abundance estimations were performed with Cufflinks v2.0.2 (Trapnell et al. 2010). Specifically, transcript abundance for a given gene was quantified by calculating the frequency of RNA-Seq reads that align to it, and was expressed as an FPKM value (a normalized value that accounts for differing gene lengths and the total number of RNA-Seq reads obtained for a given in planta or in vitro library).

Bioinformatic analyses for the identification of $C f C E$ genes.

The ORF of each gene that encodes a putative secreted, small cysteine-rich protein, as previously identified by de Wit and associates (2012), was verified using RNA-Seq-determined exon-intron boundaries provided by TopHat v2.0.4. Regions of the strain 0WU genome without a gene prediction but with RNA-Seq transcript coverage were manually investigated for an ORF using RNA-Seq-determined exon-intron boundaries, as above. Specifically, only those gene loci with a peak RNASeq read coverage of $\geq 500 \times$ and encoding a putative protein of 30 to 300 aa in length were investigated. N-terminal signal peptide predictions were carried out using SignalP v3.0 (Bendtsen et al. 2004) and v4.1 (Petersen et al. 2011). Transmembrane domain and GPI anchor predictions were performed using TMHMM v2.0 (Krogh et al. 2001) and the Big-PI Fungal Predictor (Eisenhaber et al. 2004), respectively.

\section{Expressed transcript sequence comparison.}

Fungal paired-end RNA-Seq reads from the IPO 1979-H-Cf0 compatible interaction $(125,141)$ were mapped to 58 predefined in planta-transcribed loci of strain OWU using TopHat v2.0.4. These loci represented $44 C f C E$ genes, the 12 previously cloned effector genes, and two reference housekeeping genes ( $\beta$ tubulin, JGI ID 186849; and actin, JGI ID 189818). Mapped reads were assembled into a consensus sequence using CAP3 (Huang and Madan 1999), realigned to the strain OWU ORF, and mined for SNP and indels using a custom python script.

\section{PVX-mediated expression.}

The cDNA sequence encoding the mature CfCE1 or CfCE2 protein was fused downstream of the cDNA sequence encoding the $N$. tabacum PR1A secretion signal, and cloned into the modified PVX-based binary vector pSfinx (Takken et al. 2000), with expression controlled by the Cauliflower mosaic virus $35 \mathrm{~S}$ promoter. Agrobacterium tumefaciens-mediated delivery of the resulting recombinant viruses (agroinfection) then enabled the targeted systemic production of CfCE1 or CfCE2 protein in virus-infected plants, with the PR1A signal peptide targeting secretion to the host apoplast. The recombinant viruses generated were PVX::SP-CfCE1-short and PVX::SP-CfCE1-long (encoding the PR1A signal peptide fused to the short or long mature CfCE1 protein, respectively), PVX::CfCE1-short and PVX::
CfCE1-long (encoding the short or long mature CfCE1 protein, respectively, with no signal peptide), and PVX::SP-CfCE2 (encoding the PR1A signal peptide fused to the mature CfCE2 protein). The constructs encoding these recombinant viruses (pSfinx::SP-CfCE1-short, pSfinx::SP-CfCE1-long, pSfinx:: $C f C E 1$-short, pSfinx::CfCE1-long, and pSfinx::SP-CfCE2, respectively) were generated according to Stergiopoulos and associates (2010). Specifically, to generate pSfinx::SP-CfCE1-short, pSfinx::SP-CfCE1-long, and pSfinx::SP-CfCE2, the nucleotide sequence encoding the PR1A signal peptide was first amplified by PCR from a preexisting pSfinx::Avr4 construct available in our laboratory (Takken et al. 2000) using the PRlA_AscI_F/ PRIA_R primer pair (Supplementary Table S3). PCR experiments were set up in a final volume of $20 \mu \mathrm{l}$ containing $20 \mathrm{ng}$ of cDNA template, and were carried out using Phusion Flash high fidelity PCR master mix (Finnzyme; Thermo Fisher Scientific, Waltham, MA, U.S.A.) according to the manufacturer's instructions. The nucleotide sequence encoding the mature CfCE1 or CfCE2 protein was amplified by PCR as above from cDNA derived from a compatible $0 \mathrm{WU}-\mathrm{H}-\mathrm{Cf}-0$ interaction at $8 \mathrm{dpi}$ using the CfCE1 (SP-CfCE1_PVX_short_F or SP-CfCE1_ PVX_long_F/CfCE1_PVX_NotI_R) or CfCE2 (SP-CfCE2_ PVX_F/CfCE2_PVX_NotI_R) primer pair. Here, the forward primer contained a 17 -nt $5^{\prime}$ overhang complementary to the PRIA signal peptide sequence required to fuse the PRIA signal peptide and $C f C E$ nucleotide sequences by overlap extension PCR. PCR amplicons were purified from agarose gels using an Illustra GFX PCR DNA and gel band purification kit (GE Healthcare, Milwaukee, WI, U.S.A.), as per the manufacturer's instructions, and an overlap extension PCR performed using 20 ng each of the purified $P R I A$ and $C f C E$ sequence amplicons using the PRIA_AscI_F/CfCE1_PVX_NotI_R or PRIA_AscI_F/ CfCE2_PVX_NotI_R primer pair. In doing so, the forward and reverse primers introduced a $5^{\prime}$ AscI and $3^{\prime}$ Not I restriction site, respectively. To generate the pSfinx::CfCE1-short and pSfinx:: $C f C E$ 1-long constructs, the nucleotide sequence encoding the mature CfCE1 protein was amplified by PCR from fungal cDNA as described previously using the CfCE1_PVX_short_ $A s c \mathrm{I}$ F/CfCE1_PVX_NotI_R or CfCE1_PVX_long_AscI_F/ CfCE1_PVX_NotI_R primer pair. Again, the forward and reverse primers contained a $5^{\prime}$ AscI and $3^{\prime}$ Not I restriction site, respectively. Because these constructs contained no signal peptide, the forward primer also contained a start codon preceding the nucleotide sequence encoding the mature CfCE1-short or CfCE1-long protein for initiation of translation. PCR amplicons were purified as above, cloned into pGEM-T Easy (Promega Corp., Madison, WI, U.S.A.), and transformed into subcloning efficiency DH5 $\alpha$-competent cells of Escherichia coli (Invitrogen) according to the manufacturer's instructions. Plasmid DNA was purified using a QIAprep Spin miniprep kit (Qiagen), again as per the manufacturer's instructions, and sequence authenticity was confirmed by custom DNA sequencing at Macrogen Inc. (Amsterdam) using the universal M13_F/M13_R primer pair. Correct insert DNA was isolated from pGEM-T Easy using the AscI and NotI restriction enzymes (New England Biolabs, Ipswich, MA, U.S.A.) and directionally ligated (Promega Corp.) into the polylinker region of pSfinx (opened with the same restriction enzymes), as per the manufacturer's instructions. Ligation products were transformed into $E$. coli (selection with kanamycin at $50 \mu \mathrm{g} / \mathrm{ml}$ ) (Sigma-Aldrich, St. Louis), plasmid DNA isolated as above, and sequence authenticity confirmed by DNA sequencing using the OX10_F/N31_R primer pair, which flank the cDNA fusion insert in the pSfinx backbone. A. tumefaciens GV3101 was transformed with pSfinx::SP-CfCE1-long, pSfinx::SP-CfCE1-short, pSfinx::CfCE1-long, pSfinx::CfCE1short, pSfinx::SP-CfCE2, and empty pSfinx (negative control) by electroporation (Takken et al. 2000). Transformants were 
selected on Luria-Bertani agar plates containing kanamycin at $50 \mu \mathrm{g} / \mathrm{ml}$ and $28^{\circ} \mathrm{C}$. Transformants were prepared for agroinfiltration as per Stergiopoulos and associates (2010) and, for heterologous expression, cultures were infiltrated through stomata on the abaxial side of tomato cotyledons at 10 days postgermination using a 1-ml needleless syringe. The ability to elicit an HR was assessed at 3 weeks postinoculation.

\section{Gene complementation.}

Genomic DNA of strain 0WU was extracted according to van Kan and associates (1991), and dissolved in sterile $\mathrm{H}_{2} \mathrm{O}$. A $C f C E 1$ genomic DNA fragment of 1,452 bp (comprising the complete $C f C E 1$ ORF as well as a native promoter and terminator region of 709 and $199 \mathrm{bp}$, respectively) was amplified by PCR from the genomic DNA of strain OWU, as described previously, using the CfCE1_complementation_PacI_F/CfCE1_ complementation_NotI_R primer pair. Likewise, a CfCE2 genomic DNA fragment of 2,210 bp (corresponding to the complete $C f C E 2 \mathrm{ORF}$ as well as a native promoter and terminator region of 1,049 and $883 \mathrm{bp}$, respectively) was amplified by PCR using the CfCE2_complementation_PacI_F/CfCE2_complementation_NotI_R primer pair. In each case, the forward and reverse primers introduced a $5^{\prime} \mathrm{PacI}$ and $3^{\prime}$ Not I restriction site, respectively, for directional cloning into the binary vector pFBTS1, a modified version of pFBT004 (Bolton et al. 2008) in which the ToxA promoter has been removed. PCR amplicons were purified as before, digested with the PacI and NotI restriction enzymes (New England Biolabs), and ligated into pFBTS1 (opened with the same restriction enzymes) to give the pFBTS1::CfCE1 and pFBTS1::CfCE2 constructs. Sequence authenticity was confirmed by DNA sequencing using the same primer pairs employed for PCR amplification of the CfCE1 and $C f C E 2$ genomic DNA sequences. The pFBTS1::CfCE1 and pFBTS1::CfCE2 constructs, together with the pFBTS1 empty vector (negative control), were transformed into A. tumefaciens AGL1 by electroporation, and introduced into strain IPO 1979 of C. fulvum by A. tumefaciens-mediated transformation using the protocol described by Ökmen and associates (2013), with one modification: selection media for A. tumefaciens transformants contained kanamycin at $50 \mu \mathrm{g} / \mathrm{ml}$ and rifampicin at $25 \mu \mathrm{g} / \mathrm{ml}$. For each construct, conidia from five independent fungal transformants were prepared and inoculated onto MMCf-0, MM-Cf-2, and MM-Cf-5, as described previously. The level of disease was assessed at 2 weeks postinoculation.

\section{Avr5 virulence assay.}

qrtPCR was initially used to determine which Avr5-complemented transformants of strain IPO 1979 possess a single functional copy of the Avr5 gene. For genomic DNA extraction, five independent Avr5-complemented transformants, as well as an empty vector transformant (negative control) and the wild-type IPO 1979 strain, were cultured in PDB and harvested as described previously. Genomic DNA was extracted as before and qrtPCR performed with $100 \mathrm{ng}$ of genomic DNA according to Ökmen and associates (2013). qrtPCR primer pairs were designed with Primer3 (Untergasser et al. 2012) and their efficiency and specificity were determined with a dilution series of genomic DNA prior to use. Avr5 gene copy number was inferred from hygromycin B phosphotransferase ( $h p h$ ) gene copy number using the $h p h \_q r$ PCR_F/hph_qrtPCR_R primer pair. For this purpose, the $C$. fulvum actin and $\beta$-tubulin genes were targeted for normalization and as a reference single-copy gene, respectively, using the $C f$-actin_RT-qrtPCR_F/Cf-actin_RTqrtPCR_R and $C f$ - $\beta$-tubulin_RT-qrtPCR_F/Cf- $\beta$-tubulin_RTqrtPCR_R primer pairs. Results were analyzed according to the $2^{-\Delta \overline{\mathrm{C}} \mathrm{t}}$ method (Livak and Schmittgen 2001), and are the average of three technical replicates.
IPO 1979 transformants complemented with a single functional copy of the Avr5 gene, as well as wild-type IPO 1979 and an empty vector transformant of this strain, were inoculated onto MM-Cf- 0 as described previously. The fourth composite leaf of infected tomato plants was harvested at $4,8,12$, and $16 \mathrm{dpi}$ and immediately flash frozen in liquid nitrogen. Samples were ground to a powder in liquid nitrogen, and genomic DNA was extracted from $100 \mathrm{mg}$ of material as before. To assess $C$. fulvum biomass during infection of MM-Cf-0, the actin gene of this fungus was targeted in $100 \mathrm{ng}$ of genomic DNA by qrtPCR using the $C f$-actin_RT-qrtPCR_F/Cf-actin_ RT-qrtPCR_R primer pair. For sample calibration, the $S$. $l y$ copersicum gene encoding the large subunit of ribulose-1,5bisphosphate carboxylase/oxygenase (rubisco) was targeted using the Sl-rubisco_qrtPCR_F/Sl-rubisco_qrtPCR_R primer pair. Results were analyzed according to the $2^{-\Delta \mathrm{Ct}}$ method (Livak and Schmittgen 2001) and are the average of three biological replicates. A two-way analysis of variance, followed by a Fisher's least significant difference test, was used to determine whether changes in fungal biomass between Avr5-complemented transformants and both wild-type and empty vector transformants are statistically significant $(P<0.01)$.

\section{PCR presence-or-absence screen and analysis of allelic variation.}

Strains of C. fulvum were cultured in PDB and genomic DNA extracted, as described previously. The gene presence-orabsence screen was carried out by PCR as before, with genespecific forward and reverse primers and $20 \mathrm{ng}$ of $C$. fulvum genomic DNA as template. To carry out the allelic variation screen, PCR product from the presence-or-absence screen was purified and directly sequenced using the same gene-specific primer pairs employed for the PCR presence-or-absence screen.

\section{RT-qrtPCR analysis of gene expression.}

Strain 0WU samples from a compatible 0WU-H-Cf-0 interaction at 4, 8, 12, and 16 dpi and in vitro PDB, Gamborg B5, and Gamborg B5-N liquid cultures were generated as per that described for transcriptome sequencing. Total RNA was extracted from $100 \mathrm{mg}$ of material using $1 \mathrm{ml}$ of Trizol and purified with a NucleoSpin RNA plant kit (Macherey-Nagel, Düren, Germany) according to the manufacturer's instructions. cDNA was synthesized using M-MLV reverse transcriptase (Promega Corp.) as per the manufacturer's instructions, and RT-qrtPCR experiments were performed on these cDNA samples according to Ökmen and associates (2013). RT-qrtPCR primer pairs were designed with Primer3, and their efficiency and specificity were determined with a dilution series of cDNA prior to use. The $C$. fulvum actin gene was targeted as a reference gene for normalization of gene expression, and results were analyzed according to the $2^{-\Delta \mathrm{Ct}}$ method (Livak and Schmittgen 2001). Results are the average of three biological replicates.

\section{Accession numbers.}

The Avr5 (CfCE1) and CfCE2 nucleotide sequences can be found in GenBank of the NCBI, with the accession numbers KJ452245 and KJ452246, respectively. Raw RNA-Seq read libraries for strains OWU and IPO 1979 can be found in the Sequence Read Archive of NCBI, with the BioSample accession numbers SAMN02642556 to SAMN02642561 and SAMN02642562, respectively.

\section{Additional bioinformatic analyses.}

The BLAST server (BLASTp and tBLASTn) (Altschul et al. 1997) was used to identify potential homologs of the CfCE1 and CfCE2 proteins in publicly available sequence databases at NCBI, JGI, and the Broad Institute. Variation in $\mathrm{G}+\mathrm{C}$ con- 
tent along scaffold 7180000130711 was calculated using the EMBOSS isochore server (Rice et al. 2000). BLASTn was used to identify sequence repeats shared between scaffold 7180000130711 and the rest of the C. fulvum genome.

\section{ACKNOWLEDGMENTS}

We thank J. Collemare for critically reviewing the manuscript and H. J. Bouwmeester for sourcing the funding required for RNA-Seq transcriptome sequencing of $C$. fulvum IPO 1979. Financial assistance for this research was provided by Wageningen University, the Royal Netherlands Academy of Arts and Sciences, European Research Area-Plant Genomics, and the Centre for BioSystems Genomics (CBSG; part of The Netherlands Genomics Initiative/Netherlands Organization for Scientific Research) under CBSG2012/NPC2 Proteomics Hotel Project TD8-35. C. H. Mesarich, M. H. A. Joosten and P. J. G. M. de Wit conceived the project. A. van der Burgt and C. H. Mesarich performed the bioinformatic analyses. C. H. Mesarich, S. A. Griffiths, B. Ökmen, H. G. Beenen and D. W. Etalo carried out the experimental work. C. H. Mesarich wrote the paper.

\section{LITERATURE CITED}

Altschul, S. F., Madden, T. L., Schäffer, A. A., Zhang, J., Zhang, Z., Miller, W., and Lipman, D. J. 1997. Gapped BLAST and PSI-BLAST: A new generation of protein database search programs. Nucleic Acids Res. 25:3389-3402.

Bendtsen, J. D., Nielsen, H., von Heijne, G., and Brunak, S. 2004. Improved prediction of signal peptides: SignalP 3.0. J. Mol. Biol. 340:783-795.

Bolton, M. D., van Esse, H. P., Vossen, J. H., de Jonge, R., Stergiopoulos, I., Stulemeijer, I. J. E., van den Berg, G. C. M., Borrás-Hidalgo, O., Dekker, H. L., de Koster, C. G., de Wit, P. J. G. M., Joosten, M. H. A J., and Thomma, B. P. H. J. 2008. The novel Cladosporium fulvum lysin motif effector Ecp6 is a virulence factor with orthologues in other fungal species. Mol. Microbiol. 69:119-136.

Bruce, M., Neugebauer, K. A., Joly, D. L., Migeon, P., Cuomo, C. A., Wang, S., Akhunov, E., Bakkeren, G., Kolmer, J. A, and Fellers, J. P. 2014. Using transcription of six Puccinia triticina races to identify the effective secretome during infection of wheat. Front. Plant Sci. 4:520.

Cantu, D., Segovia, V., MacLean, D., Bayles, R., Chen, X., Kamoun, S., Dubcovsky, J., Saunders, D., and Uauy, C. 2013. Genome analyses of the wheat yellow (stripe) rust pathogen Puccinia striiformis f. sp. tritici reveal polymorphic and haustorial expressed secreted proteins as candidate effectors. BMC Genomics 14:270.

de Jonge, R., Peter van Esse, H., Kombrink, A., Shinya, T., Desaki, Y., Bours, R., van der Krol, S., Shibuya, N., Joosten, M. H. A. J., and Thomma, B. P. H. J. 2010. Conserved fungal LysM effector Ecp6 prevents chitin-triggered immunity in plants. Science 329:953-955.

de Jonge, R., van Esse, H. P., Maruthachalam, K., Bolton, M. D., Santhanam, P., Saber, M. K., Zhang, Z., Usami, T., Lievens, B., Subbarao, K. V., and Thomma, B. P. 2012. Tomato immune receptor Ve1 recognizes effector of multiple fungal pathogens uncovered by genome and RNA sequencing. Proc. Natl. Acad. Sci. U.S.A. 109:5110-5115.

de Wit, P. J., Mehrabi, R., van den Burg, H. A., and Stergiopoulos, I. 2009a. Fungal effector proteins: Past, present and future. Mol. Plant Pathol. 10:735-747.

de Wit, P. J. G. M. 1992. Molecular characterization of gene-for-gene systems in plant-fungus interactions and the application of avirulence genes in control of plant pathogens. Annu. Rev. Phytopathol. 30:391-418.

de Wit, P. J. G. M., and Spikman, G. 1982. Evidence for the occurrence of race and cultivar-specific elicitors of necrosis in intercellular fluids of compatible interactions of Cladosporium fulvum and tomato. Physiol. Plant Pathol. 21:1-11.

de Wit, P. J. G. M., Joosten, M. H. A. J., Thomma, B. P. H. J., and Stergiopoulos, I. 2009b. Gene for gene models and beyond: The Cladosporium fulvum-tomato pathosystem. Pages 135-156 in: The Mycota V: Plant Relationships, 2nd ed. H.B. Deising, ed. Springer, Berlin.

de Wit, P. J. G. M., van der Burgt, A., Ökmen, B., Stergiopoulos, I., AbdElsalam, K. A., Aerts, A. L., Bahkali, A. H., Beenen, H. G., Chettri, P. Cox, M. P., Datema, E., de Vries, R. P., Dhillon, B., Ganley, A. R., Griffiths, S. A., Guo, Y., Hamelin, R. C., Henrissat, B., Kabir, M. S., Jashni, M. K., Kema, G., Klaubauf, S., Lapidus, A., Levasseur, A., Lindquist, E., Mehrabi, R., Ohm, R. A., Owen, T. J., Salamov, A., Schwelm, A., Schijlen, E., Sun, H., van den Burg, H. A., van Ham, R. C. H. J., Zhang, S., Goodwin, S. B., Grigoriev, I. V., Collemare, J., and Bradshaw, R. E. 2012. The genomes of the fungal plant pathogens Cladosporium fulvum and Dothistroma septosporum reveal adaptation to different hosts and lifestyles but also signatures of common ancestry. PLoS Genet. 8:e1003088. Published online.

Dixon, M. S., Jones, D. A., Keddie, J. S., Thomas, C. M., Harrison, K., and Jones, J. D. G. 1996. The tomato $C f$-2 disease resistance locus comprises two functional genes encoding leucine-rich repeat proteins. Cell 84:451459.

Dixon, M. S., Hatzixanthis, K., Jones, D. A., Harrison, K., and Jones, J. D. G. 1998. The tomato $C f-5$ disease resistance gene and six homologs show pronounced allelic variation in leucine-rich repeat copy number. Plant Cell 10:1915-1925.

Dixon, M. S., Golstein, C., Thomas, C. M., van der Biezen, E. A., and Jones, J. D. G. 2000. Genetic complexity of pathogen perception by plants: The example of $R c r 3$, a tomato gene required specifically by $C f$ 2. Proc. Natl. Acad. Sci. U.S.A. 97:8807-8814.

Eisenhaber, B., Schneider, G., Wildpaner, M., and Eisenhaber, F. 2004. A sensitive predictor for potential GPI lipid modification sites in fungal protein sequences and its application to genome-wide studies for Aspergillus nidulans, Candida albicans, Neurospora crassa, Saccharomyces cerevisiae and Schizosaccharomyces pombe. J. Mol. Biol. 337:243-253.

Fu, Y. H., and Marzluf, G. A. 1990. nit-2, the major positive-acting nitrogen regulatory gene of Neurospora crassa, encodes a sequence-specific DNA-binding protein. Proc. Natl. Acad. Sci. U.S.A. 87:5331-5335.

Gout, L., Kuhn, M. L., Vincenot, L., Bernard-Samain, S., Cattolico, L., Barbetti, M., Moreno-Rico, O., Balesdent, M. H., and Rouxel, T. 2007. Genome structure impacts molecular evolution at the AvrLm1 avirulence locus of the plant pathogen Leptosphaeria maculans. Environ. Microbiol. 9:2978-2992.

Hacquard, S., Joly, D. L., Lin, Y. C., Tisserant, E., Feau, N., Delaruelle, C., Legué, V., Kohler, A., Tanguay, P., Petre, B., Frey, P., van de Peer, Y., Rouzé, P., Martin, F., Hamelin, R.C., and Duplessis, S. 2012. A comprehensive analysis of genes encoding small secreted proteins identifies candidate effectors in Melampsora larici-populina (poplar leaf rust). Mol. Plant-Microbe Interact. 25:279-293.

Hammond-Kosack, K. E., Staskawicz, B. J., Jones, J. D. G., and Baulcombe, D. C. 1995. Functional expression of a fungal avirulence gene from a modified potato virus X genome. Mol. Plant-Microbe Interact. 8:181-185.

Huang, X., and Madan, A. 1999. CAP3: A DNA sequence assembly program. Genome Res. 9:868-877.

Hubbeling, N. 1978. Breakdown of resistance of the $C f 5$ gene in tomato by another new race of Fulvia fulva. Meded. Fac. Landbouwwet Rijksuniv. Gent 43:891-894.

Iida, Y., Iwadate, Y., Kubota, M., and Terami, F. 2010. Occurrence of a new race 2.9 of leaf mold of tomato in Japan. J. Gen. Plant Pathol. 76:84-86.

Joosten, M. H. A. J., Cozijnsen, T. J., and de Wit, P. J. G. M. 1994. Host resistance to a fungal tomato pathogen lost by a single base-pair change in an avirulence gene. Nature 367:384-386.

Kerr, E. A., Patrick, Z. A., and Bailey, D. L. 1971. Resistance in tomato species to new races of leaf mold (Cladosporium fulvum Cke.) Hortic. Res. 11:84-92.

Krogh, A., Larsson, B., von Heijne, G., and Sonnhammer, E. L. 2001. Predicting transmembrane protein topology with a hidden Markov model: Application to complete genomes. J. Mol. Biol. 305:567-580.

Krüger, J., Thomas, C. M., Golstein, C., Dixon, M. S., Smoker, M., Tang, S., Mulder, L., and Jones, J. D. 2002. A tomato cysteine protease required for $C f$-2-dependent disease resistance and suppression of autonecrosis. Science 296:744-747.

Kruijt, M., de Kock, M. J., and de Wit, P. J. 2005. Receptor-like proteins involved in plant disease resistance. Mol. Plant Pathol. 6:85-97.

Laterrot, H., and Clerjeau, M. 1979. Détermination des pathotypes de Fulvia fulva (= Cladosporium fulvum) présents sur tomate dans les serres françaises. Ann. Amélior. Plant. 29:447-462.

Laterrot, H., Gerlagh, M., Ester, A., and Stamova, L. 1985. Race 2.5, a new race of Cladosporium fulvum (Fulvia fulva) on tomato. Neth. J. Plant Pathol. 91:41-47.

Laugé, R., Joosten, M. H. A. J., van den Ackerveken, G. F. J. M., van den Broek, H. W. J., and de Wit, P. J. G. M. 1997. The in planta-produced extracellular proteins ECP1 and ECP2 of Cladosporium fulvum are virulence factors. Mol. Plant-Microbe Interact. 10:725-734.

Laugé, R., Goodwin, P. H., de Wit, P. J. G. M., and Joosten, M. H. A. J. 2000. Specific HR-associated recognition of secreted proteins from Cladosporium fulvum occurs in both host and non-host plants. Plant J. 23:735-745.

Livak, K. J., and Schmittgen, T. D. 2001. Analysis of relative gene expression data using real-time quantitative PCR and the $2^{-\Delta \Delta C T}$ method. Methods 25:402-408.

Luderer, R., Takken, F. L. W., de Wit, P. J. G. M., and Joosten, M. H. A. J. 2002. Cladosporium fulvum overcomes $C f$-2-mediated resistance by producing truncated AVR2 elicitor proteins. Mol. Microbiol. 45:875-884.

Ökmen, B., Etalo, D. W., Joosten, M. H. A. J., Bouwmeester, H. J., de Vos, 
R. C. H., Collemare, J., and de Wit, P. J. G. M. 2013. Detoxification of $\alpha$-tomatine by Cladosporium fulvum is required for full virulence on tomato. New Phytol. 198:1203-1214.

Pérez-García, A., Snoeijers, S. S., Joosten, M. H., Goosen, T., and de Wit, P. J. 2001. Expression of the avirulence gene Avr 9 of the fungal tomato pathogen Cladosporium fulvum is regulated by the global nitrogen response factor NRF1. Mol. Plant-Microbe Interact. 14:316-325.

Petersen, T. N., Brunak, S., von Heijne, G., and Nielsen, H. 2011. SignalP 4.0: Discriminating signal peptides from transmembrane regions. Nat. Methods 8:785-786.

Ravagnani, A., Gorfinkiel, L., Langdon, T., Diallinas, G., Adjadj, E., Demais, S., Gorton, D., Arst, H. N., and Scazzocchio, C. 1997. Subtle hydrophobic interactions between the seventh residue of the zinc finger loop and the first base of an HGATAR sequence determine promoterspecific recognition by the Aspergillus nidulans GATA factor AreA. EMBO (Eur. Mol. Biol. Organ.) J. 16:3974-3986.

Rice, P., Longden, I., and Bleasby, A. 2000. EMBOSS: The European molecular biology open software suite. Trends Genet. 16:276-277.

Rivas, S., and Thomas, C. M. 2005. Molecular interactions between tomato and the leaf mold pathogen Cladosporium fulvum. Annu. Rev. Phytopathol. 43:395-436.

Rooney, H. C., van't Klooster, J. W., van der Hoorn, R. A., Joosten, M. H., Jones, J. D., and de Wit, P. J. 2005. Cladosporium Avr2 inhibits tomato Rcr3 protease required for $C f$-2-dependent disease resistance. Science 308:1783-1786.

Sánchez-Vallet, A., Saleem-Batcha, R., Kombrink, A., Hansen, G., Valkenburg, D. J., Thomma, B. P., and Mesters, J. R. 2013. Fungal effector Ecp6 outcompetes host immune receptor for chitin binding through intrachain LysM dimerization. eLife 2:e00790.

Seear, P. J., and Dixon, M. S. 2003. Variable leucine-rich repeats of tomato disease resistance genes $C f-2$ and $C f-5$ determine specificity. Mol. Plant Pathol. 4:199-202.

Shabab, M., Shindo, T., Gu, C., Kaschani, F., Pansuriya, T., Chintha, R., Harzen, A., Colby, T., Kamoun, S., and van der Hoorn, R. A. 2008. Fungal effector protein AVR2 targets diversifying defense-related cys proteases of tomato. Plant Cell 20:1169-1183.

Snoeijers, S.S., Pérez-García, A., Goosen, T., and de Wit, P. J. G. M. 2003. Promoter analysis of the avirulence gene Avr 9 of the fungal tomato pathogen Cladosporium fulvum in the model filamentous fungus Aspergillus nidulans. Curr. Genet. 43:96-102.

Sone, T., Takeuchi, S., Miki, S., Satoh, Y., Ohtsuka, K., Abe, A., and Asano, K. 2013. Homologous recombination causes the spontaneous deletion of AVR-Pia in Magnaporthe oryzae. FEMS (Fed. Eur. Microbiol. Soc.) Microbiol. Lett. 339:102-109.

Stamova, L. 1982. A new race of Cladosporium fulvum Cooke on tomato in Bulgaria. Gradinar. Lozar. Nauka 19:89-94.

Stergiopoulos, I., and de Wit, P. J. 2009. Fungal effector proteins. Annu. Rev. Phytopathol. 47:233-263.

Stergiopoulos, I., de Kock, M. J. D., Lindhout, P., and de Wit, P. J. G. M. 2007a. Allelic variation in the effector genes of the tomato pathogen Cladosporium fulvum reveals different modes of adaptive evolution. Mol. Plant-Microbe Interact. 20:1271-1283.

Stergiopoulos, I., Groenewald, M., Staats, M., Lindhout, P., Crous, P. W., and de Wit, P. J. 2007b. Mating-type genes and the genetic structure of a world-wide collection of the tomato pathogen Cladosporium fulvum. Fungal Genet. Biol. 44:415-429.

Stergiopoulos, I., van den Burg, H. A., Ökmen, B., Beenen, H. G., van Liere, S., Kema, G. H. J., and de Wit, P. J. G. M. 2010. Tomato Cf resistance proteins mediate recognition of cognate homologous effectors from fungi pathogenic on dicots and monocots. Proc. Natl. Acad. Sci. U.S.A. 107:7610-7615.

Stergiopoulos, I., Kourmpetis, Y. A. I., Slot, J. C., Bakker, F. T., de Wit, P. J. G. M., and Rokas, A. 2012. In silico characterization and molecular evolutionary analysis of a novel superfamily of fungal effector proteins. Mol. Biol. Evol. 29:3371-3384.

Takken, F. L., Luderer, R., Gabriels, S. H., Westerink, N., Lu, R., de Wit, P. J., and Joosten, M. H. 2000. A functional cloning strategy, based on a binary PVX-expression vector, to isolate HR-inducing cDNAs of plant pathogens. Plant J. 24:275-283.

Thomma, B. P., Nurnberger, T., and Joosten, M. H. 2011. Of PAMPs and effectors: The blurred PTI-ETI dichotomy. Plant Cell 23:4-15.

Thomma, B. P. H. J., van Esse, H. P., Crous, P. W., and de Wit, P. J. G. M. 2005. Cladosporium fulvum (syn. Passalora fulva), a highly specialized plant pathogen as a model for functional studies on plant pathogenic Mycosphaerellaceae. Mol. Plant Pathol. 6:379-393.

Thomma, B. P. H. J., Bolton, M. D., Clergeot, P.-H., and de Wit, P. J. G. M. 2006. Nitrogen controls in planta expression of Cladosporium fulvum Avr9 but no other effector genes. Mol. Plant Pathol. 7:125-130.

Tigchelaar, E. C. 1984. Collections of isogenic tomato stocks. Rep. Tomato Genet. Coop. 34:55-57.
Trapnell, C., Pachter, L., and Salzberg, S. L. 2009. TopHat: Discovering splice junctions with RNA-Seq. Bioinformatics 25:1105-1111.

Trapnell, C., Williams, B. A., Pertea, G., Mortazavi, A., Kwan, G., van Baren, M. J., Salzberg, S. L., Wold, B. J., and Pachter, L. 2010. Transcript assembly and quantification by RNA-Seq reveals unannotated transcripts and isoform switching during cell differentiation. Nat. Biotechnol. 28:511-515.

Untergasser, A., Cutcutache, I., Koressaar, T., Ye, J., Faircloth, B. C. Remm, M., and Rozen, S. G. 2012. Primer3-new capabilities and interfaces. Nucleic Acids Res. 40:e115.

van den Ackerveken, G. F., van Kan, J. A., Joosten, M. H., Muisers, J. M., Verbakel, H. M., and de Wit, P. J. 1993. Characterization of two putative pathogenicity genes of the fungal tomato pathogen Cladosporium fulvum. Mol. Plant-Microbe Interact. 6:210-215.

van den Ackerveken, G. F. J. M., Dunn, R. M., Cozijnsen, A. J., Vossen, J. P. M. J., Broek, H. W. J., and de Wit, P. J. G. M. 1994. Nitrogen limitation induces expression of the avirulence gene $a v r 9$ in the tomato pathogen Cladosporium fulvum. Mol. Gen. Genet. 243:277-285.

van den Burg, H. A., Westerink, N., Francoijs, K. J., Roth, R., Woestenenk, E., Boeren, S., de Wit, P. J., Joosten, M. H., and Vervoort, J. 2003. Natural disulfide bond-disrupted mutants of AVR4 of the tomato pathogen Cladosporium fulvum are sensitive to proteolysis, circumvent $C f-4$ mediated resistance, but retain their chitin binding ability. J. Biol. Chem. 278:27340-27346.

van den Burg, H. A., Spronk, C. A., Boeren, S., Kennedy, M. A., Vissers, J. P., Vuister, G. W., de Wit, P. J., and Vervoort, J. 2004. Binding of the AVR4 elicitor of Cladosporium fulvum to chitotriose units is facilitated by positive allosteric protein-protein interactions: The chitin-binding site of AVR4 represents a novel binding site on the folding scaffold shared between the invertebrate and the plant chitin-binding domain. J. Biol. Chem. 279:16786-16796.

van den Burg, H. A., Harrison, S. J., Joosten, M. H., Vervoort, J., and de Wit, P. J. 2006. Cladosporium fulvum Avr4 protects fungal cell walls against hydrolysis by plant chitinases accumulating during infection. Mol. Plant-Microbe Interact. 19:1420-1430.

van den Hooven, H. W., van den Burg, H. A., Vossen, P., Boeren, S., de Wit, P. J., and Vervoort, J. 2001. Disulfide bond structure of the AVR9 elicitor of the fungal tomato pathogen Cladosporium fulvum: Evidence for a cystine knot. Biochemistry 40:3458-3466.

van der Burgt, A., Severing, E., Collemare, J., and de Wit, P. 2014. Automated alignment-based curation of gene models in filamentous fungi. BMC Bioinf. 15:19.

van de Wouw, A. P., Lowe, R. G., Elliott, C. E., Dubois, D. J., and Howlett, B. J. 2013. An avirulence gene, AvrLmJ1, from the blackleg fungus, Leptosphaeria maculans, confers avirulence to Brassica juncea cultivars. Mol. Plant Pathol. 15:523-530.

van Esse, H. P., Bolton, M. D., Stergiopoulos, I., de Wit, P. J., and Thomma, B. P. 2007. The chitin-binding Cladosporium fulvum effector protein Avr4 is a virulence factor. Mol. Plant-Microbe Interact. 20:1092-1101.

van Esse, H. P., van't Klooster, J. W., Bolton, M. D., Yadeta, K. A., van Baarlen, P., Boeren, S., Vervoort, J., de Wit, P. J., and Thomma, B. P. 2008. The Cladosporium fulvum virulence protein Avr2 inhibits host proteases required for basal defense. Plant Cell 20:1948-1963.

van Kan, J. A., van den Ackerveken, G. F., and de Wit, P. J. 1991. Cloning and characterization of cDNA of avirulence gene $a v r 9$ of the fungal pathogen Cladosporium fulvum, causal agent of tomato leaf mold. Mol. Plant-Microbe Interact. 4:52-59.

van't Klooster, J. W., van der Kamp, M. W., Vervoort, J., Beekwilder, J. Boeren, S., Joosten, M. H., Thomma, B. P., and de Wit, P. J. 2011. Affinity of Avr2 for tomato cysteine protease Rcr3 correlates with the Avr2-triggered Cf-2-mediated hypersensitive response. Mol. Plant Pathol. 12:21-30.

Westerink, N., Brandwagt, B. F., de Wit, P. J. G. M., and Joosten, M. H. A. J. 2004. Cladosporium fulvum circumvents the second functional resistance gene homologue at the $C f-4$ locus $(H c r 9-4 E)$ by secretion of a stable avr4E isoform. Mol. Microbiol. 54:533-545.

\section{AUTHOR-RECOMMENDED INTERNET RESOURCES}

Big-PI Fungal Predictor database: mendel.imp.ac.at/gpi/fungi_server.html Broad Institute website: www.broad.mit.edu

The European Molecular Biology Open Software Suite (EMBOSS)

Isochore database: emboss.bioinformatics.nl/cgi-bin/emboss/isochore Joint Genome Institute (JGI) website: www.jgi.doe.gov

The National Center for Biotechnology Information (NCBI) website: www.ncbi.nlm.nih.gov

SignalP v3.0 database: www.cbs.dtu.dk/services/SignalP-3.0

SignalP v4.1 database: www.cbs.dtu.dk/services/SignalP

TMHMM v2.0 database: www.cbs.dtu.dk/services/TMHMM 